\title{
Fracture Characteristics and Fatigue Damage of Noncoplanar Fractured Rocklike Specimens under Uniaxial Graded Cyclic Loading and Unloading
}

\author{
Gui-cheng He, ${ }^{1,2}$ Wen-yuan Wu $\mathbb{D}^{1,2}$ Yun Wang, ${ }^{1,2}$ Yong-ming Xue $\mathbb{D}^{1,2}$ Bing Dai, ${ }^{1,2}$ \\ and Zhi-jun Zhang ${ }^{1,2}$ \\ ${ }^{1}$ School of Resources Environment and Safety Engineering, University of South China, Hengyang, China \\ ${ }^{2}$ Hunan Province Engineering Technology, Research Center for Disaster Prediction and Control on Mining Geotechnical Engineering, \\ 421001 Hengyang, China
}

Correspondence should be addressed to Wen-yuan Wu; wwyuan94@163.com

Received 27 March 2021; Accepted 26 April 2021; Published 10 May 2021

Academic Editor: Zhengyang Song

Copyright (@) 2021 Gui-cheng He et al. This is an open access article distributed under the Creative Commons Attribution License, which permits unrestricted use, distribution, and reproduction in any medium, provided the original work is properly cited.

\begin{abstract}
To study the fracture characteristics and fatigue damage of fractured rock masses, noncoplanar fractured rocklike specimens prepared using cement mortar were used for a graded cyclic loading-unloading test. The results showed that the two ends of the horizontal crack were the main stress concentration areas, and they inhibited crack initiation of the inclined fracture. With increasing crack inclination, the inhibitory effect became more obvious. Under the condition that the lower limit stress is constant, as the upper limit stress increases, energy dissipation of the specimen increases, becoming relatively stable in each stage of the cycle. With increasing crack inclination, the increase in the energy dissipation value decreases. Specimens with large changes in the shape of their hysteresis loop tend to exhibit large fluctuations in the elastic modulus. As the loading progressed, the elastic modulus exhibited a downward trend, and the damping ratio tended to be stable. The change in the damping ratio is affected by the dynamic elastic modulus and area of the hysteresis loop. Based on the Weibull probability distribution function, the evolution curve of the damage variable of the specimen can be obtained. This curve reflects the trend of the damage change of the rocklike specimens under various levels of cyclic loading and unloading.
\end{abstract}

\section{Introduction}

Rock mass is the main bearing carrier in large-scale projects in fields such as mining, transportation, and water conservation. The rocks in special engineering locations such as mining areas, railways, bridges, tunnels, and other infrastructure are subject to complex loads. When subjected to periodic loads, such as repeated excavation and backfilling, blasting, and earthquakes, the bearing capacity and stability of rocks will decrease. The fatigue damage caused by the change in rock mechanical properties and the gradual deterioration of rock performance affect the safety of engineering activities. With the increasing construction scale of various engineering projects, rock mechanics problems are becoming increasingly complicated. Engineering accidents and economic losses caused by rock stability problems have attracted the attention of many scholars [1-5]. To study the mechanical response and failure characteristics of rocks under periodic loads is vital to assess the stability and safety of rock mass engineering.

Various researchers [6-10] have found that, under the action of cyclic loading, the upper limit stress and amplitude are the main factors affecting the fatigue life of rocks, and they have put forward the viewpoint of fatigue threshold. By analyzing the mechanics, energy, and deformation characteristics of rocks under uniaxial cyclic loading and unloading, it was found that the unloading elastic modulus was greater than the loading elastic modulus under cyclic loading. In the aforementioned research, constant-amplitude cyclic loading and unloading of stress was mainly adopted, but the actual cyclic loading of the rock mass fluctuates within a certain range and is not a constant value. Therefore, some 
scholars have studied the mechanical response and fatigue characteristics of rocks under the action of cyclic loading and unloading in stages. Peng et al. [11] studied the influence of the change in the lower limit of stress on the deformation characteristics of sandstone during cyclic loading and unloading and found that the elastic modulus and Poisson's ratio of the sample increased significantly with an increase in the lower limit of stress. Sun et al. [12] studied the evolution law of fatigue damage of rocks under different confining pressures under cyclic loading conditions and obtained an evolution curve. They found that the curve-fitting degree increased with an increase in the confining pressure. $\mathrm{Li}$ et al. [13] conducted uniaxial cyclic loading-unloading tests on sandstone, analyzed the evolutionary process of rock damage, established a theoretical model between the axial strain and the number of cycles, and derived the damage variable evolution equation. Other researchers considered the fatigue characteristics of rocks under different stress amplitudes of loading and unloading [14-16] but did not fully consider rock masses with structural planes, such as fractures and joints. In fact, most rock masses are neither complete nor completely discrete media. The fractured rock will undergo crack initiation, expansion, and penetration during the failure process. The evolution of the crack dominates the failure of the fractured rock mass. Therefore, in a study of intermittent fractured media under cyclic loading, Li et al. [17] established a fractured rock mass damage model from the perspective of energy dissipation and introduced the concept of an equivalent modulus. Liu et al. [18] and Li et al. [19] studied the mechanical properties of jointed rock masses under cyclic loading, explained the evolution of crack propagation, and established a jointed rock mass damage model.

In conclusion, few scholars have fully considered the strength characteristics, energy dissipation, and fatigue damage of fractured rock masses under the action of cyclic loading and unloading. Because rock masses are a geological material with initial defects, it is crucial to study the mechanical properties, crack propagation, and energy evolution of fractured rock masses under the action of nonconstant cyclic stress. Therefore, in this study, we used cyclic loading tests with varying stresses to study the guiding effect of different inclination angles of noncoplanar fractures on crack propagation and the fatigue damage caused by cyclic loading of different stress amplitudes to fractured rocks. The experimental conclusions were drawn by analyzing the hysteretic loop characteristics, energy dissipation, and fatigue damage characteristics. The research results should provide useful guidance for the safety and stability of geotechnical engineering construction projects.

\section{Experimental Materials and Procedures}

2.1. Sample Preparation. In [20-22], cement mortar was used as the rocklike material, with the ratio of white cement:fine sand $:$ water $=5: 5: 2$. First, oil was applied to the surface of a stainless steel sheet (of thickness $=0.4 \mathrm{~mm}$ ) and inserted into a stainless steel mold with internal (length $\times$ width $\times$ height) dimensions of $150 \mathrm{~mm} \times 50 \mathrm{~mm} \times 200 \mathrm{~mm}$; the mixed mortar was then poured and evenly vibrated. After the cement mortar was initially set, the embedded steel sheet was pulled out to form a prefabricated crack, the mold was removed $24 \mathrm{~h}$ after the test piece was formed, and the qualified test piece was placed in the curing box for standard curing for 28 days. The test blocks were divided into groups A and B. Group A was a double-slit specimen, and group B was a three-slit specimen. The distance between the midpoints of the primary and secondary fissures remained unchanged at $20 \mathrm{~mm}$, the fissure width was $0.4 \mathrm{~mm}$, the main fissure was $30 \mathrm{~mm}$ long, and the secondary fissures were $20 \mathrm{~mm}$ long and rotated $0^{\circ}, 30^{\circ}, 45^{\circ}$, $60^{\circ}$, and $90^{\circ}$ along their midpoints. The sample model is shown in Figures 1 and 2. (A00 indicates a double-crack specimen, in which the level of the main crack remains unchanged, and the angle $\alpha$ between the secondary crack and the horizontal plane is $0^{\circ}$.)

2.2. Test Scheme. The RMT-150 rock mechanics loading test machine was used for the indoor loading test, as shown in Figure 3. The test was conducted in two steps: first, each sample was subjected to uniaxial compression to obtain its uniaxial compressive strength and its stress-strain curve; second, the sample was subjected to a graded cyclic loadingunloading test. By taking $40 \%$ of the compressive strength of the sample obtained in the first step as the lower limit, the initial upper limit was $80 \%$. During the loading process, the lower limit of stress remained unchanged. After every 300 cycles, the upper limit of stress was increased by $5 \%$ until the sample broke. Force control was used in the two-step test, with a loading rate of $0.5 \mathrm{kN} / \mathrm{s}$, a sine wave used as a loading waveform during cyclic loading and unloading, and a loading frequency of $0.2 \mathrm{~Hz}$.

2.3. Sample-Related Parameters. The relevant data obtained from the laboratory loading test on the specimens are listed in Table 1.

\section{Results and Analysis}

3.1. Characteristics of the Cyclic Loading-Unloading Curve. The uniaxial compression curves of a sample obtained in the test with the stress-strain curve under the action of a graded cyclic load are shown in Figures 4 and 5. Under the action of cyclic loading and unloading, the curves of the unfractured sample and that with cracks and the uniaxial compression curve roughly intersect in the postpeak area, and the uniaxial compression curve basically includes the grading cyclic loading-unloading curve. This phenomenon indicates that, under cyclic loading, the stress-strain curve of either unfractured or fractured rock is controlled by the uniaxial compression curve. The reason for the fatigue failure of the rock mass is that the deformation has reached the limit value, and the deformation of the fatigue failure is equivalent to the corresponding deformation in the postpeak zone under a static load. The fatigue deformation evolution of the intermittent fractured rock mass is consistent with that of unfractured rock and can be divided into three stages: initial deformation, constant-rate deformation, and accelerated deformation. When the load reached point $\mathrm{A}$, the stress reached $80 \%$ of the peak stress, and the specimen entered the initial deformation stage of fatigue failure. In the $\mathrm{AB}$ stage, 

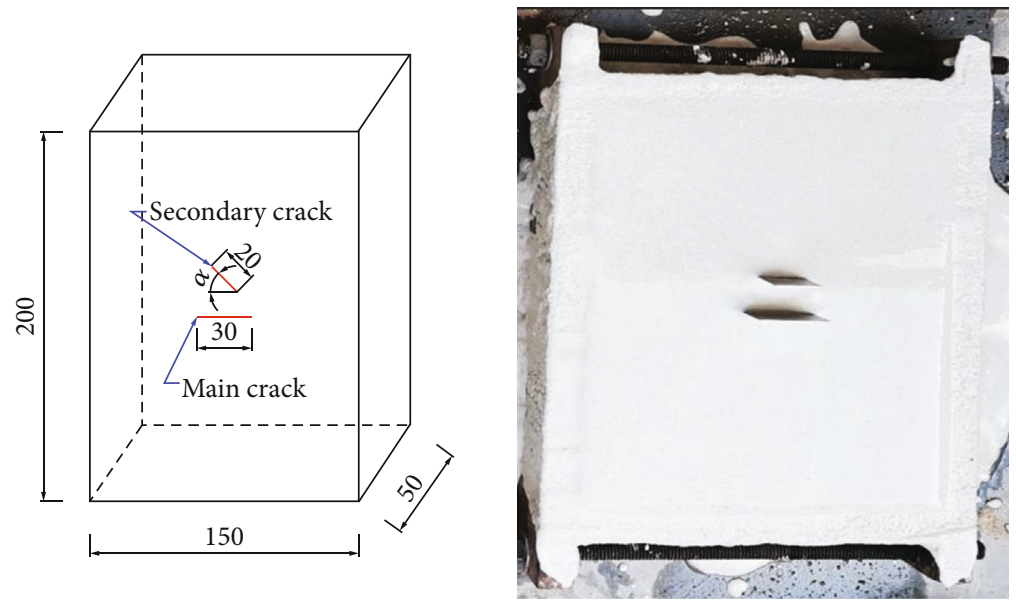

Figure 1: Model and production diagram of a group A specimen (in units of mm).
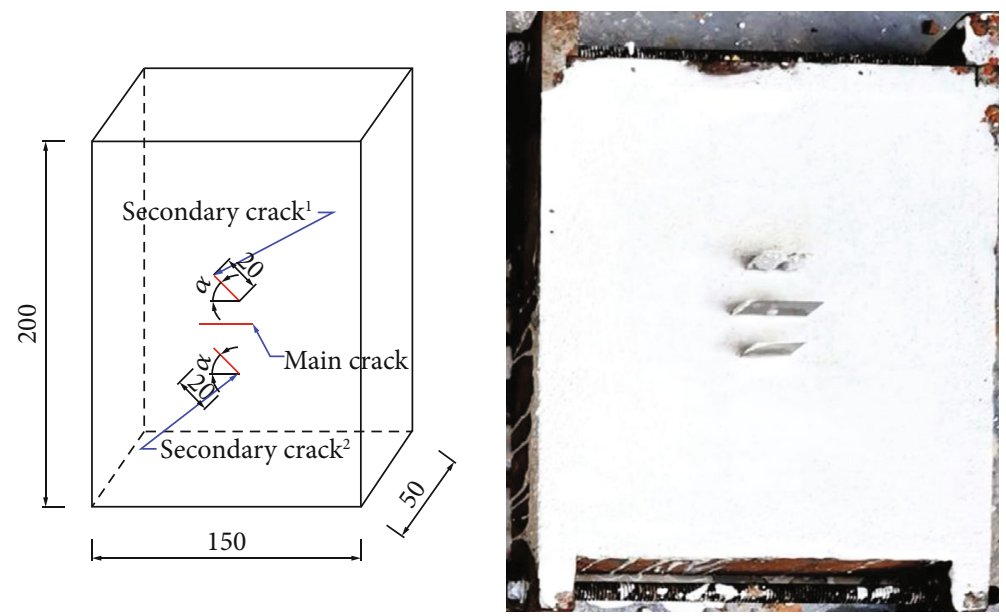

Figure 2: Model and production diagram of a group B specimen (in units of mm).

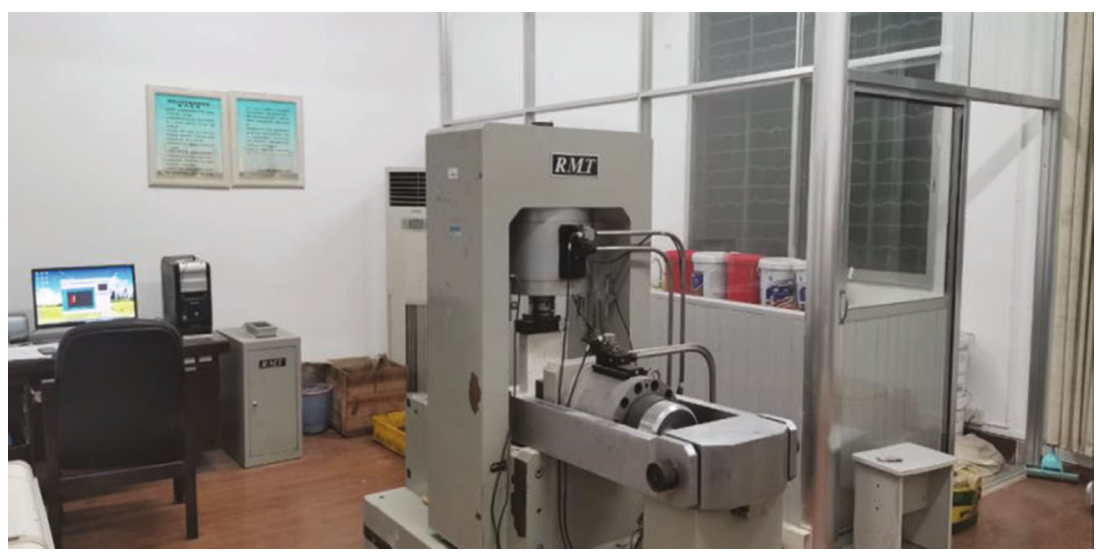

FIgURE 3: RMT-150 rock mechanics test system.

the area of the hysteresis loop was relatively small, the distribution was relatively sparse, and the curve formation rate was uniform; the prefabricated cracks began to crack, and the horizontal cracks were gradually compacted. As the loading-unloading cycle progressed, the sample entered segment $\mathrm{BC}$ of the constant-rate deformation stage. During this stage, the maximum stress was $85 \%$ of the peak stress, the curve formation rate was relatively low, the shape of the hysteresis loop changed, the area increased, and the distribution was relatively dense. Observing the surface of the specimen reveals that the initiating cracks had further evolved, and the primary and secondary cracks had penetrated; segment 
TABle 1: Physical parameters of the samples.

\begin{tabular}{lcccccccc}
\hline $\begin{array}{l}\text { Serial } \\
\text { number }\end{array}$ & $\begin{array}{c}\text { Length } \\
(\mathrm{mm})\end{array}$ & $\begin{array}{c}\text { Width } \\
(\mathrm{mm})\end{array}$ & $\begin{array}{c}\text { Height } \\
(\mathrm{mm})\end{array}$ & $\begin{array}{c}\text { Fracture dip } \\
\text { angle }\left(^{\circ}\right)\end{array}$ & $\begin{array}{c}\text { Failure strength under } \\
\text { static load }(\mathrm{MPa})\end{array}$ & $\begin{array}{c}\text { Cycle failure } \\
\text { strength }(\mathrm{MPa})\end{array}$ & $\begin{array}{c}\text { Number of } \\
\text { cycles }\end{array}$ & $\begin{array}{c}\text { Cyclic series } \\
(\text { level })\end{array}$ \\
\hline Unfractured & 149.6 & 50.0 & 199.5 & $/$ & 43.210 & 38.357 & 626 \\
A00 & 149.2 & 49.5 & 199.4 & $00-00$ & 35.980 & 31.381 & 3 \\
A30 & 150.0 & 49.2 & 198.8 & $30-00$ & 37.549 & 31.917 & 364 \\
A45 & 149.5 & 48.6 & 199.2 & $45-00$ & 38.256 & 34.376 & 652 \\
A60 & 149.4 & 49.5 & 198.6 & $60-00$ & 36.387 & 34.568 & 873 \\
A90 & 149.6 & 49.5 & 199.5 & $90-00$ & 40.725 & 37.874 & 577 \\
B00 & 149.5 & 49.6 & 199.3 & $00-00-00$ & 36.520 & 33.613 & 5 \\
B30 & 148.8 & 49.2 & 199.4 & $30-00-30$ & 38.601 & 32.811 & 2 \\
B45 & 149.2 & 49.4 & 199.5 & $45-00-45$ & 39.621 & 35.499 & 317 \\
B60 & 149.6 & 48.8 & 198.8 & $60-00-60$ & 36.984 & 35.005 & 615 \\
B90 & 149.5 & 49.6 & 199.5 & $90-00-90$ & 40.301 & 36.883 & 938 \\
\hline
\end{tabular}

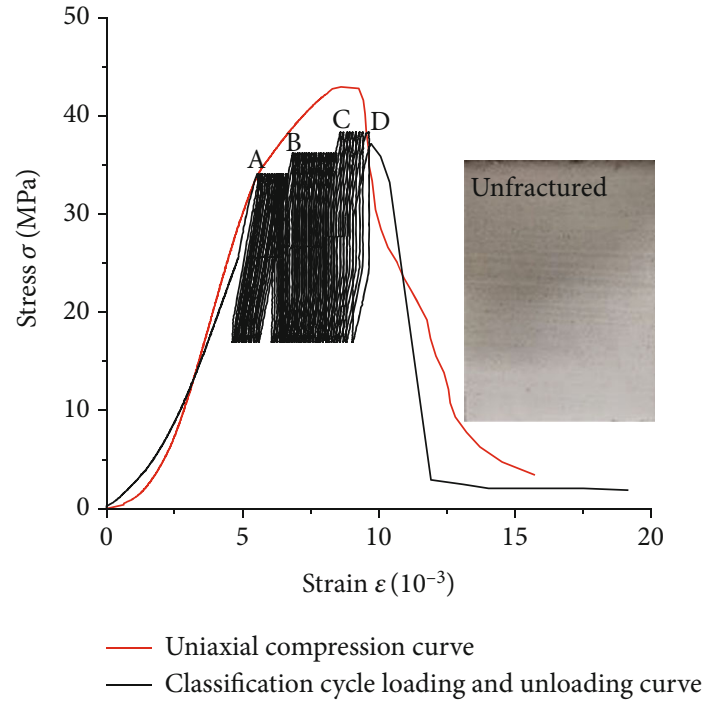

FIGURE 4: Stress-strain curves for the unfractured sample under two loading modes.

$\mathrm{CD}$ is the accelerated deformation stage. During this stage, the maximum stress reached $90 \%$ of the peak stress, the curve was formed rapidly, and the hysteretic loop distribution became looser. The surface of the sample was partially lumped off until the whole sample broke and lost its bearing capacity. The stress drop of the cyclic loading-unloading curve when the specimen broke occurred faster than that under uniaxial compression, which means that the degree of damage to the rocklike specimen under cyclic load was greater, with obvious brittle failure characteristics.

3.2. Analysis of Intensity Characteristics. The existence of cracks destroys the integrity of the rock mass. Their size and location distribution greatly affect the failure mechanism of the rock mass and cause the strength of the rock mass to decrease. As shown in Figure 6, the peak strength of the cracked sample first increased, then decreased, and then increased with the change in the inclination angle, and the strength was lower than that of the unfractured sample.
The bearing capacity of the sample was the highest when the crack direction was consistent with the stress direction. In the samples of group B, the existence of secondary subcracks had a strengthening effect on the bearing capacity of the specimen. This strengthening is also reflected in the grading cyclic loading-unloading process. Samples with the same angle were destroyed in the same cyclic series. The failure strength of the specimen under cyclic loading was consistent with the variation under uniaxial compression. Under the action of grading cyclic loading and unloading, the number of cracks had only a minor effect on the number of cycles. As shown in Figure 7, the number of cycles for the two groups of $\mathrm{AB}$ samples increased with the inclination angle $\alpha$ when the main crack remained constant. For most of them, the number of cycles first decreased, then increased, and then decreased again, and the values were almost the same.

3.3. Crack Evolution and Failure Pattern. By combining the stress-strain curve and the overall situation of specimen failure, the deformation failure process of the specimen can be roughly divided into four stages: compaction, microcrack propagation, unstable fracture, and complete failure. Group A samples were selected to describe the crack evolution and failure morphology, as shown in Figure 8.

Crack growth of the specimens was simultaneously affected by the change in crack inclination and stress amplitude [23-27]. During the compression process, the prefabricated cracks in specimen A00 were gradually compacted. After the cyclic loading-unloading stage was entered, the vertical tensile cracks generated in the middle of the secondary cracks continued to expand upward as the loading progressed. The tensile cracks at the tips of the primary and secondary cracks produced lap joints, which evolved into shear cracks on both sides of the specimen after the lap joints and extended to the ends. A few far-field cracks were also observed. After specimens A30, A45, and A60 were compressed, the main cracks were gradually compacted, and the main cracks produced upward pull cracks at a certain distance from the tip of the cracks. The specific positions of the initiation were affected by the secondary cracks. The expansion has a guiding effect, and finally, the cracks overlap 


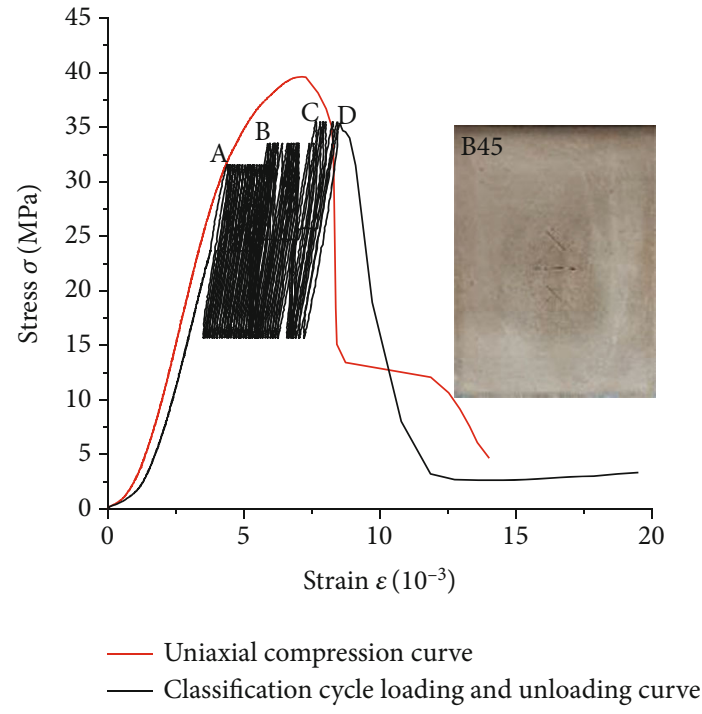

Figure 5: Stress-strain curves for the fractured sample under two loading modes.

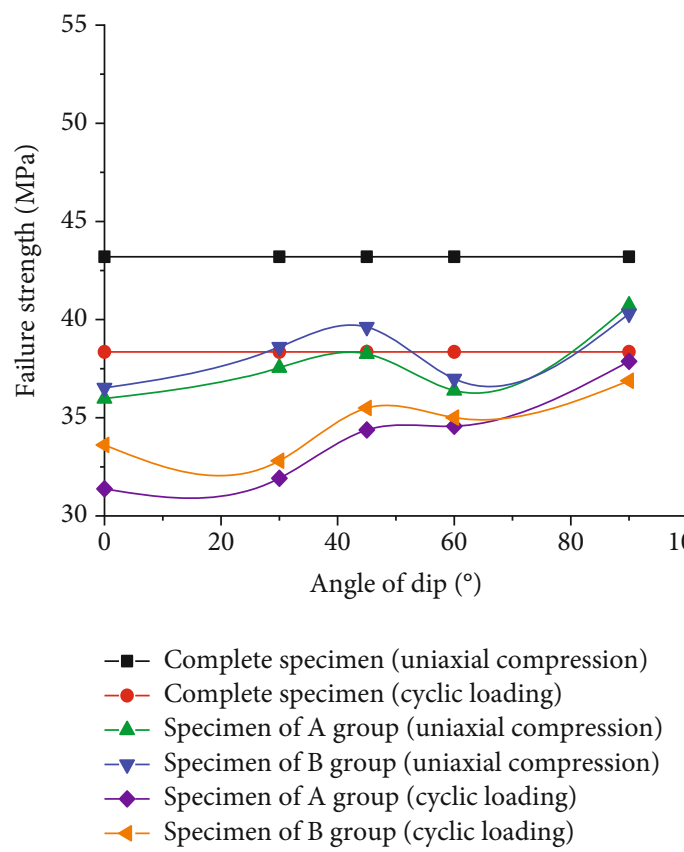

FIGURE 6: Failure strength of rocklike samples.

and penetrate the lower tip of the secondary fissure. However, as the loading progressed, the cracks initiating from the original main crack that overlapped with the inclined secondary cracks partially disappeared. It can be observed that airfoil cracks were generated at the tip of the secondary crack, and the tensile cracks generated at the tip of the main crack gradually evolved into shear cracks. These extended to the end of the specimen, and the upper tensile crack at the left tip of the main crack overlapped with the upper tip of the secondary crack to form a trough. The secondary crack of specimen A90 was in the same direction as the loading stress. During the loading process, the tensile crack in the middle of

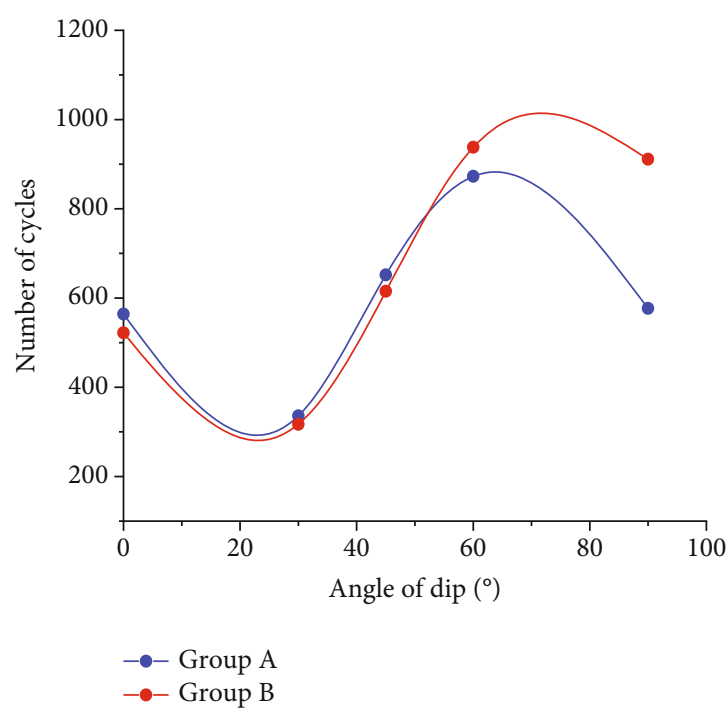

FIgURE 7: Variation of the number of cycles of group A and B samples as a function of the dip angle.

the main crack penetrated the lower tip of the secondary crack, the upper tip of the secondary crack produced vertical cracks, and the upper and lower tensile cracks were generated at the tip of the main crack. As the loading progressed, the tensile cracks gradually extended and expanded. By observing the crack evolution process, it was found that the horizontal main crack inhibited crack initiation of the inclined crack. With an increase in the inclination angle, the inhibitory effect became more obvious. This is reflected in the fact that as the inclination angle increased, the distribution of cracks on the front of the specimen decreased, and, when the inclination angle was large, far-field cracks rarely appeared. When the inclination angles of the secondary fissures were $30^{\circ}, 45^{\circ}$, and $60^{\circ}$, the stress concentration was mainly at the two ends of the horizontal fissure and at the distal end of the secondary fissure. The propagation of airfoil cracks generated by the inclined secondary cracks did not lead to the ultimate failure of the specimen; when the inclination angles of the secondary cracks were $0^{\circ}$ and $90^{\circ}$, the stress was mainly concentrated at both ends of the horizontal cracks. With an increase in the loading stress, the tensile cracks generated at both ends evolved into shear cracks and expanded to the side of the specimen. During the compression process of the specimens in group B, like group A, the horizontal cracks are gradually compacted, and the secondary crack 1 has a guiding effect on the crack initiation of the horizontal main crack. The specific position of the crack initiation is affected by the angle of the inclined crack. As the loading progresses, the tip of the primary fissure overlaps with the tip of the secondary crack1, as shown in specimens B30, B45, and B60. Airfoil cracks generated by inclined cracks will not lead to the final broken section. Parallel double cracks have a strengthening effect on the compressive strength of the specimens of group B, which is not only reflected in the final breaking strength but also reflected in the number of observable cracks on the surface of the specimens of group B than that of group A, as shown in Figure 8 . 

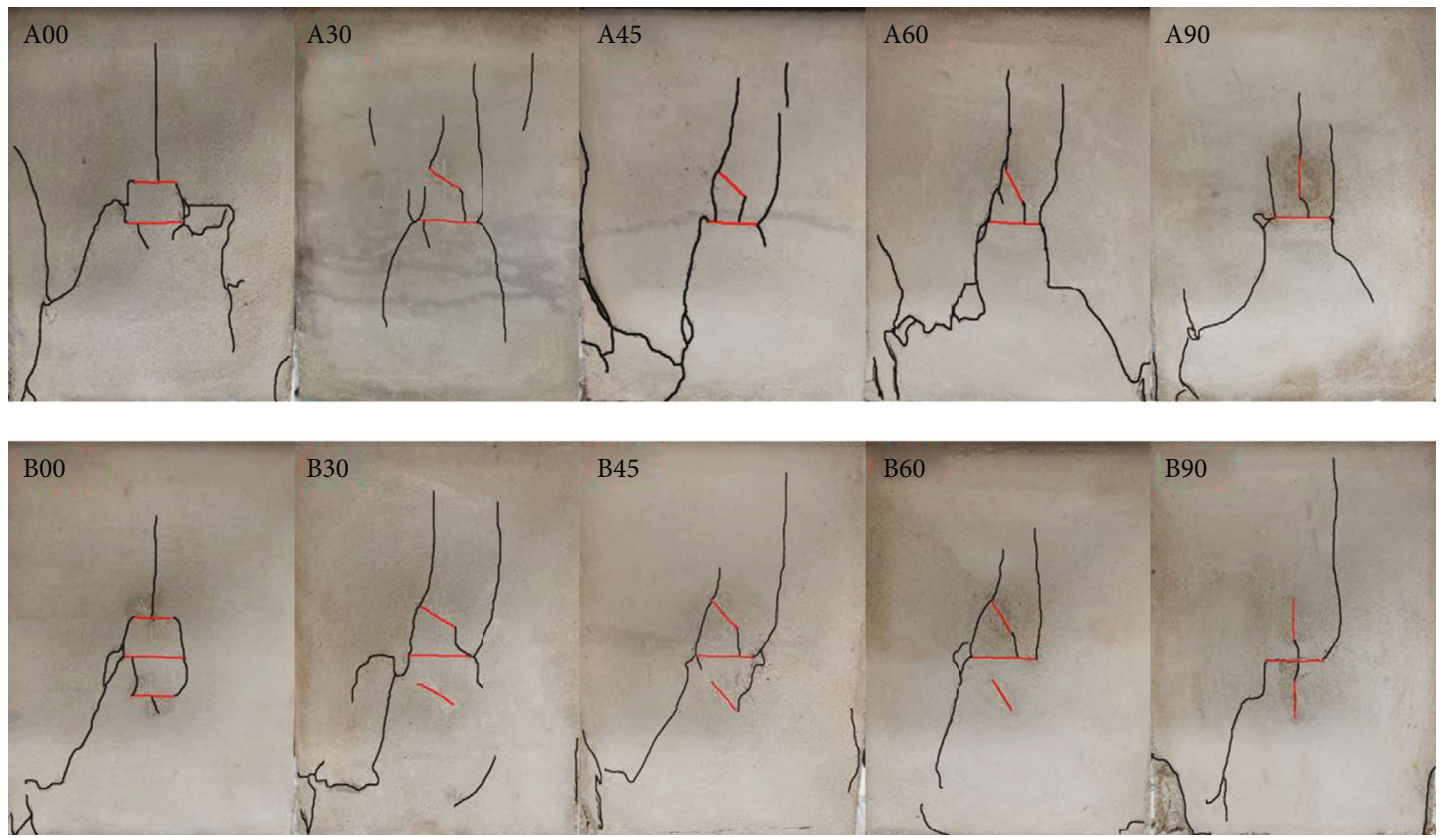

FIgURE 8: Crack propagation in the samples.

As the stress increased, cracks continued to occur, cracks penetrated through, and irreversible deformation increased. When the volume of the specimen began to expand, its end and the rigid cushion block will be subjected to an end effect owing to the frictional force. At this time, the specimen entered the unstable fracture stage, and it spalls and squeezes and expands at the main crack in the middle. When the failure strength was reached, the specimen entered the complete failure stage. At this stage, the fatigue damage of the rock specimen was severe, and the cracks expanded rapidly. The macroscopic sliding fracture surface was formed rapidly, even when the test block was broken and fragments collapsed, which is reflected in the curve falling rapidly. The specimen exhibited severe brittleness, accompanied by a "popping" sound when it was broken.

3.4. Analysis of Hysteresis Loop Characteristics. Numerous studies have been conducted on the shape of hysteresis loops [28-31]. There are certain disputes regarding their specific shapes. Rock properties affect the shape of the hysteresis loop, and the stress amplitude of loading-unloading cycles will also affect its shape. In this study, a rectangular parallelepiped specimen with prefabricated cracks was used to conduct a uniaxial-graded cyclic loading-unloading test. The hysteresis loop obtained in the test is neither an ellipse nor a crescent nor a long eggplant shape, but it is similar to a quadrilateral. Taking the stress-strain curve of the sample B90 as an example, as shown in Figure 9, we take the first hysteresis loop of each level cycle for comparative analysis.

During the cycle loading-unloading process, the unloading and reloading curves intersect under the unloading point to form a hysteresis loop. The relative relationship between the loading and unloading curves determines the area and shape of the hysteresis loop. The hysteresis loop generated at the beginning of the first stage is relatively narrow and long, and the upper and lower ends of the hysteresis loop become sharp because of the hysteresis effect produced during the closing and opening of the cracks. After entering the second-level loading-unloading cycle, the shape of the hysteresis loop changes and resembles a parallelogram. It can be observed that the second- and third-level curves are more variable. Before the sample broke, the curve tended to be flat. This change is related to the friction of the particles inside the sample. Crack evolution is related to crack penetration, and the microdamage to the specimen causes residual deformation or irreversible deformation of the rock; consequently, the loading-unloading curve exhibits nonlinear characteristics.

After each cycle of loading and unloading, the endpoint of strain and stress on the hysteresis loop increased, and the specimen underwent plastic deformation. According to the stress-strain curve of sample B90, the change in strain at each level of cyclic loading and unloading can be obtained, as shown in Figure 10: the strain of the first cycle increased by a factor of 1.9. The initial cracks and microcracks in the structure of the specimen and the particle spacing were gradually compacted after 300 cycles of loading and unloading at a lower stress amplitude; therefore, the deformation of the specimen was relatively large. After the second-level cycle, the strain grew by a factor of 0.69 . At this stage, because the specimen was quite hard, the strain change was much lower than that during the first stage. The amount of plastic deformation of the specimen was low, indicating a more obvious strain-hardening phenomenon. The growth in strain in the third-level cycle was a factor of 0.865 , which was higher than that in the second-level cycle. The relatively hard specimens began to deteriorate under the higher stress amplitude loading and unloading, and obvious crack growth appeared on the surface. After the fourth cycle was entered, the highest 

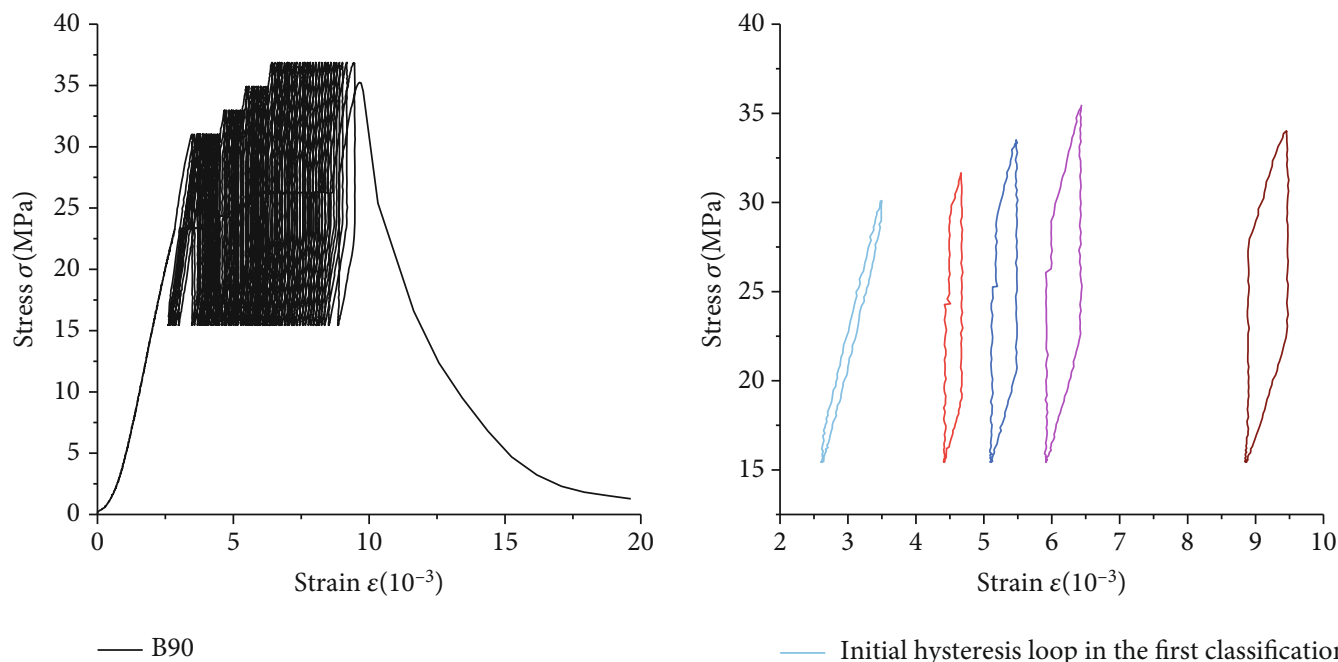

- Initial hysteresis loop in the first classification cycle

- Initial hysteresis loop in the second classification cycle

_ Initial hysteresis loop in the third classification cycle

_ Initial hysteresis loop in the fourth classification cycle

- Hysteresis loop before destruction

FIGURE 9: Comparison diagram of stress-strain curve and hysteresis loop for sample B90.

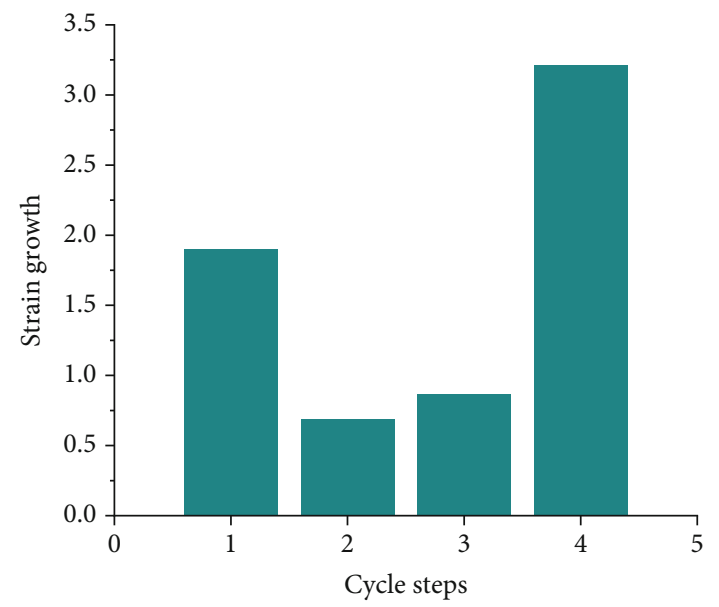

The value of strain growth

FIGURE 10: Variation in strain change versus cycle steps.

stress reached $95 \%$ of the peak stress, and the fatigue deformation of the specimen increased sharply and eventually failed. The strain grew by a factor of 3.215, and the larger the value, the greater was the degree of damage to the rock.

\section{Analysis of Energy Dissipation, Dynamic Elastic Modulus, and Damping Ratio}

Figure 11 shows that the hysteresis loop of cyclic loading and unloading is a closed loop. The area integral under the loading curve is the total work done by the external force on the rock sample, and the area integral under the unloading curve is the elastic strain energy of the rock. The total work minus the elastic strain energy is the energy dissipated in the rock, which is the area of the hysteresis loop. At each level of the

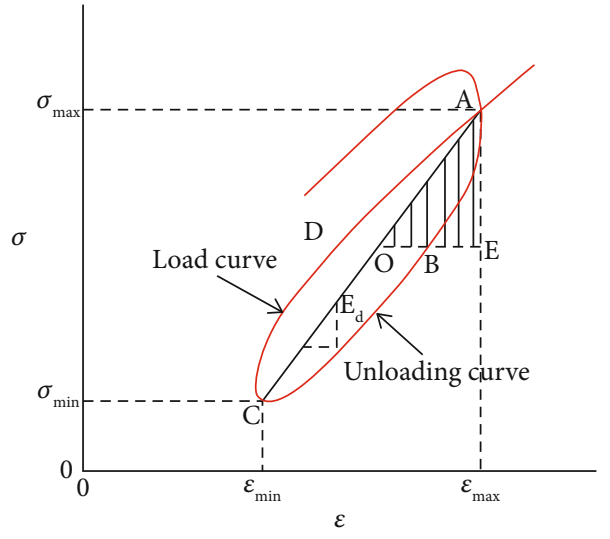

FIGURE 11: Stress-strain hysteresis loop.

loop curve, a part of the hysteresis loop is selected and applied to the calculation.

The damping ratio $\gamma$ and dynamic elastic modulus $E_{d}$ of a single cycle are defined as [32]

$$
\gamma=A /\left(4 \pi A_{s}\right),
$$

and

$$
E_{d}=\left(\sigma_{\max }-\sigma_{\min }\right) /\left(\varepsilon_{\max }-\varepsilon_{\min }\right),
$$

where $A$ is the area of the hysteresis loop $\mathrm{ABCDA} ; A_{s}$ is the area of the triangle AOE; $E_{d}$ is the elastic modulus; $\sigma_{\max }$ and $\sigma_{\min }$ are the corresponding maximum and minimum stresses in the hysteresis loop, respectively; and $\varepsilon_{\max }$ and $\varepsilon_{\min }$ are the corresponding maximum and minimum strains in the hysteretic loop, respectively.

4.1. Energy Dissipation. The size of the hysteresis loop area indicates the amount of energy dissipation during the 


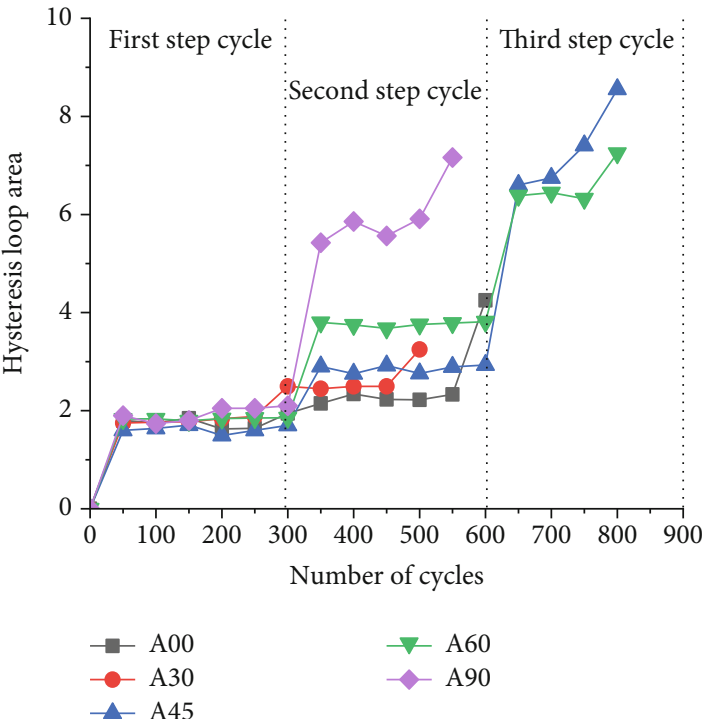

(a)

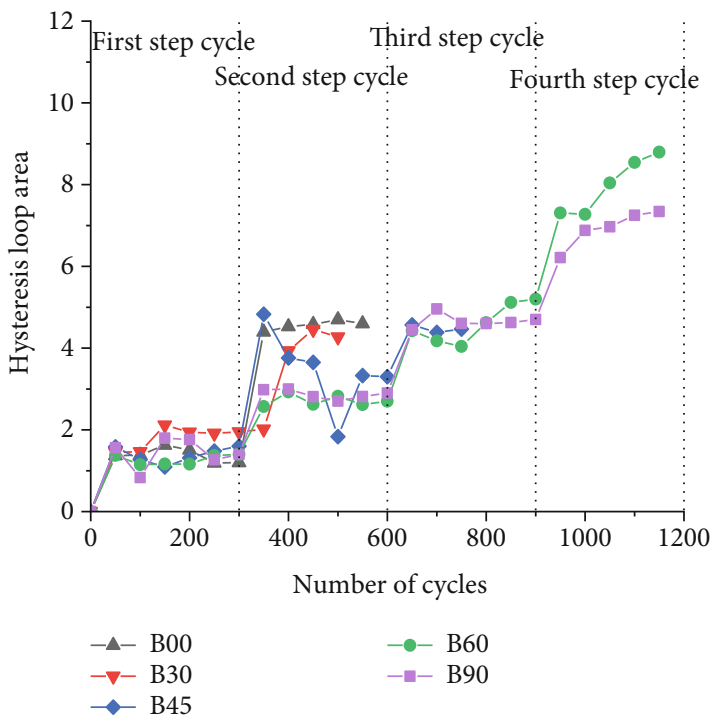

(b)

FIgURE 12: Hysteresis loop area curves for group A and B samples.

loading-unloading cycle. During cyclic loading and unloading, the initiation and expansion of microcracks and the penetration between prefabricated cracks consume part of the energy; the remaining energy is used to overcome the damping force and perform work. As shown in Figure 12, at each level of cyclic loading before the specimen was damaged, the hysteresis loop area curve was relatively flat, indicating that plastic deformation inside the specimen did not change significantly during the loading-unloading process at the same level and that energy dissipation was relatively stable. During the failure stage, the area of the hysteresis loop increased sharply, indicating that the energy of the specimen was unstable and that plastic deformation was more significant. Changing the upper limit of the stress changes the energy distribution. As the stress amplitude increased, the energy dissipation also increased. By combining these results with the observation of the stress-strain curve during the loading process, it is found that the hysteresis loops of some test blocks appear to change shape, overlap, and become offset during the loading process. These effects are related to the change in the crack inclination angle of the test specimen and the dispersion of internal particles. The shape of the hysteresis loop and the formation rate of the stress-strain curve were relatively constant. As the upper limit stress amplitude increased, the area of the hysteresis loop increased slightly.

4.2. Elastic Modulus. As shown in Figure 13, the sizes of the hysteresis loop areas of specimens A00 and A30 were essentially the same. As the number of cycles increased, the elastic modulus fluctuated slightly. Specimens A30, A60, and A90 exhibited obvious strengthening when entering the failure level cycle, B group specimens entering the second cycle exhibited an increase in their dynamic elastic moduli compared with their initial values, and specimens B30, B60, and B90 exhibited obvious strengthening in the first cycle. As the loading progressed, the elastic modulus exhibited a downward trend in the failure level cycle, indicating that, when the macroscopic crack is at a higher stress level, the initiation, propagation, and penetration of the cracks will attenuate the elastic modulus of the specimen. The change in elastic modulus corresponds to the complicated change in the stress-strain relationship curve of the specimen. During the loading process, it can be found that the stress-strain curve exhibited a large lateral shift and hysteresis loop coverage.

4.3. Evolution of the Damping Ratio. The evolution of the damping ratio curve is affected by the area of the hysteresis loop and the dynamic elastic modulus. As shown in Figure 14, in the same cycle, the damping ratio of the group A specimens does not change significantly, while that of group B group specimens fluctuates relatively more. During the initial cycle, the damping ratios are all $\sim 0.15$, and the damping ratios are all concentrated at $\sim 0.4$ at the final failure stage. After 300 cycles of loading and unloading under the first-level stress amplitude, the damping ratio increased after increasing the stress amplitude. Among them, the energy dissipation of specimens A00 and A30 was relatively stable during the loading process; consequently, the damping ratio was basically unchanged. Sample B45 exhibited complex changes during the second cycle, which may be due to damage leading to a greater deterioration of performance and unstable energy dissipation to overcome the damping force. Combined with the failure process, these findings also indicate that, when the crack inclination angle was $45^{\circ}$, the cracks in the specimen with three cracks evolved until the end of tensile-shear mixed penetration, which caused the specimen to exhibit different curve characteristics.

4.4. Damage Variable Analysis. If the initial damage caused by the prefabricated cracks is ignored, and we assume that the strength of the microelement of the rocklike specimen 


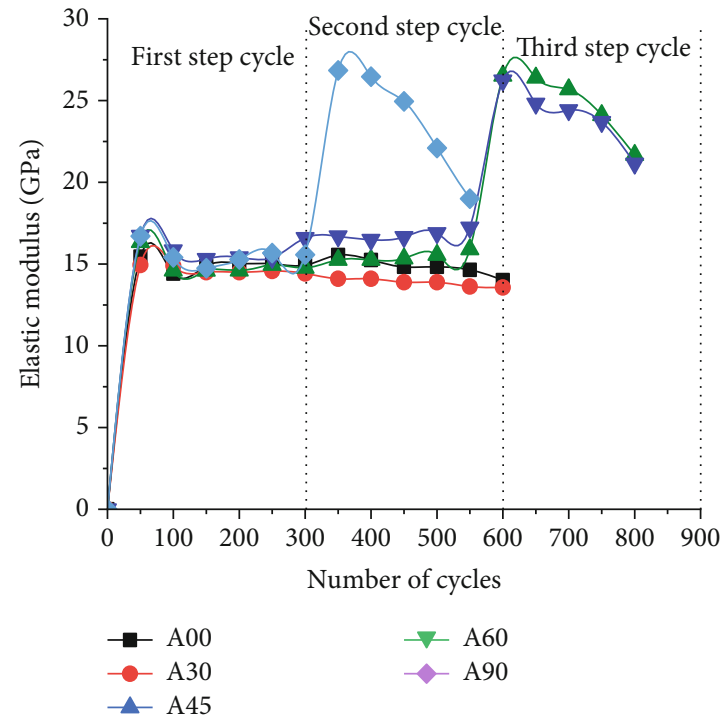

(a)

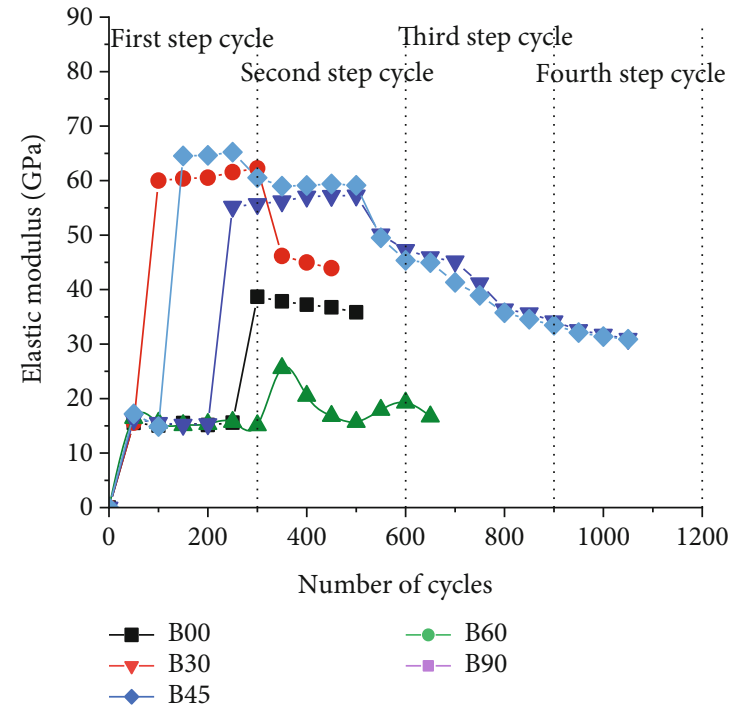

(b)

Figure 13: Dynamic elastic modulus curves for groups A and B.

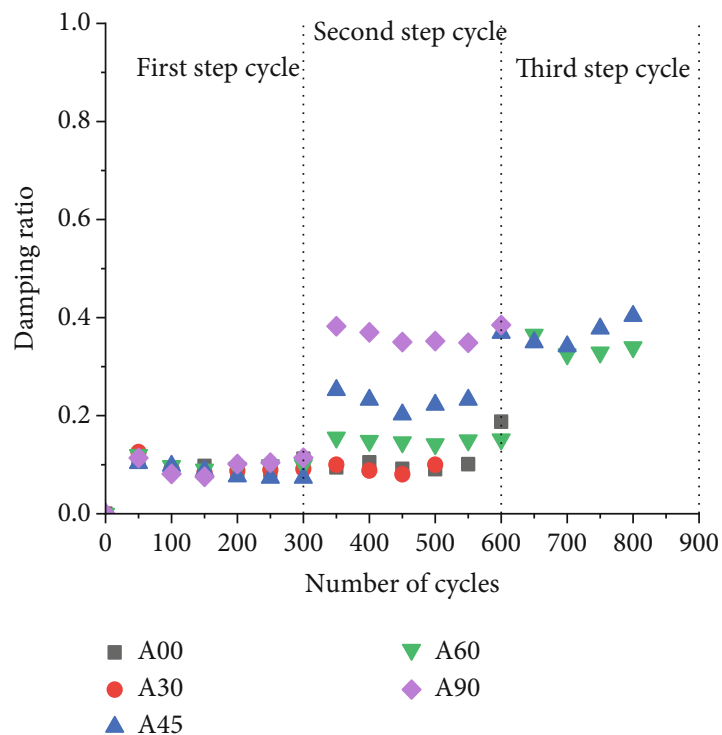

(a)

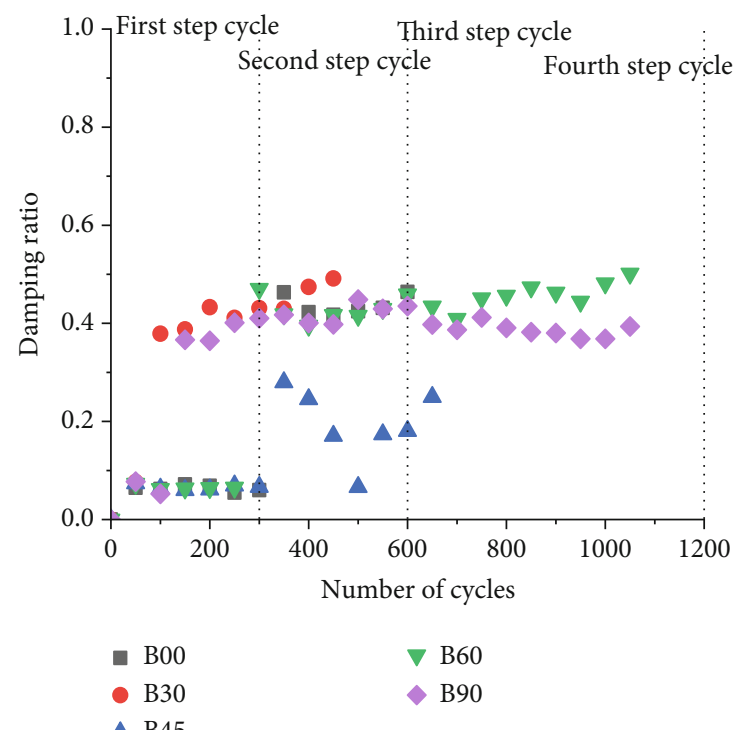

(b)

FIgURE 14: Damping ratio curves for groups A and B.

satisfies the Weibull distribution, then the probability density function is [33]

$$
p(\varepsilon)=\frac{m}{\varepsilon_{0}}\left(\frac{\varepsilon}{\varepsilon_{0}}\right)^{m-1} \exp \left[-\left(\frac{\varepsilon}{\varepsilon_{0}}\right)^{m}\right]
$$

where $p(\varepsilon)$ is the microelement strength distribution function of the rocklike specimen, $\varepsilon$ is the strain, and $m$ and $\varepsilon_{0}$ are the distribution parameters.

Let us introduce the damage variable $D$, which is defined as

$$
D=\frac{n}{N},
$$

where $n$ is the number of microelements damaged under a certain level of cyclic loading and unloading and $N$ is the total number of microelements of rocklike specimens.

When cyclic loading and unloading reaches a certain strain $\varepsilon$, the number of broken cells is

$$
n=\int_{0}^{\varepsilon} N P(\varepsilon) d_{\varepsilon}=N\left\{1-\exp \left[-\left(\frac{\varepsilon}{\varepsilon_{0}}\right)^{m}\right]\right\} .
$$

Then, the damage variable is

$$
D=1-\exp \left[-\left(\frac{\varepsilon}{\varepsilon_{0}}\right)^{m}\right] .
$$


TABLE 2: Distribution parameters.

\begin{tabular}{lcc}
\hline Cyclic loading-unloading series & $m$ & $\varepsilon_{0}$ \\
\hline & 1.365 & 5.376 \\
First step cycle & 1.223 & 5.494 \\
& 1.195 & 5.514 \\
\hline \multirow{2}{*}{ Second step cycle } & 0.530 & 1.784 \\
& 0.507 & 1.689 \\
& 0.470 & 1.511 \\
\hline
\end{tabular}

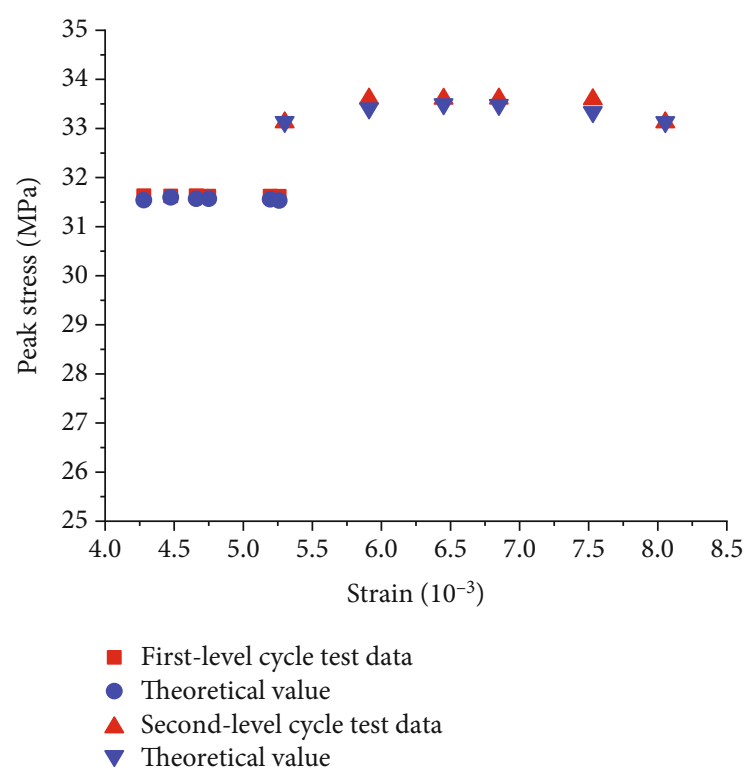

FIGURE 15: Comparison between experimental data and theoretical values.

When $D=0$, the rocklike specimen is not damaged; when $0<D<1$, the rocklike specimen has different degrees of damage; when $D=1$, the rocklike specimen is damaged.

From the rock damage constitutive model [34-37], under uniaxial compression, assuming that the microelement of the rocklike specimen satisfies the generalized Hooke's law before failure, we can obtain

$$
\sigma=E \varepsilon(1-D)
$$

where $E$ is the average dynamic elastic modulus of each number cycle and $\varepsilon$ is the strain.

By substituting Equation (6) into Equation (7), the damage constitutive relation of the rocklike cyclic loadingunloading stage in the one-dimensional state can be obtained as

$$
\sigma=E \varepsilon \exp \left[-\left(\frac{\varepsilon}{\varepsilon_{0}}\right)^{m}\right]
$$

The function $s(e)$ is derived as follows:

$$
\sigma^{\prime}(\varepsilon)=E \exp \left[-\left(\frac{\varepsilon}{\varepsilon_{0}}\right)^{m}\right]\left[1-m\left(\frac{\varepsilon}{\varepsilon_{0}}\right)^{m}\right] .
$$

Because the stress-strain relationship curve satisfies $\sigma_{\max }{ }^{\prime}\left(\varepsilon_{\max }\right)=0$, then

$$
\begin{gathered}
m=\frac{1}{\ln \left(E \varepsilon_{\max }\right)-\ln \sigma_{\max }}, \\
\varepsilon_{0}=\varepsilon_{\max } \sqrt[m]{m}
\end{gathered}
$$

In Equations (10) and (11), $\sigma_{\max }$ and $\varepsilon_{\max }$ are the peak stress and strain values of each level cycle of the rocklike specimen, respectively.

By taking specimen B00 as an example, three hysteresis loops were selected in the curve of each level. The distribution parameters $m$ and $\varepsilon_{0}$ of the rocklike sample can be calculated according to Equations (10) and (11), and the results are listed in Table 2.

The average values of the distribution parameters $m$ and $\varepsilon_{0}$ in Table 2 were used to calculate Equation (8), and the theoretical values obtained were compared with the experimental data to construct Figure 15. It can be found that the experimental values and the theoretical values basically coincide, indicating that the selection of the distribution parameters is relatively reasonable. Substituting the distribution parameters into Equation (6) to calculate the damage variable gives the fitting curve of the resulting damage evolution shown in Figure 16. The damage evolution curve reflects the change in damage to the specimen during the entire loading process. During the linear loading and the first cycle stage, the prefabricated cracks gradually compacted and cracks began to grow, but the stress on the specimen was at a lower amplitude and so the damage increased relatively steadily. As the loading progressed, microcracks within the specimen continued to develop, and the cracks expanded and combined. When the secondary cyclic loading stage was entered, the damage value rose sharply to 0.8 . At this stage, there was a slight fluctuation in the damage value, and the surface of the specimen began to partially peel off and the crack extended to the side of the end of the specimen. When the damage accumulated to 0.89 , the specimen was destroyed instantaneously, demonstrating its obvious brittleness, but the specimen still had a certain residual strength after it was destroyed. Owing to the existence of prefabricated cracks, the specimen had initial damage; therefore, the damage value $\mathrm{D}$ did not reach 1 during the failure.

Based on the Weibull probability distribution function, the fitting curve of the damage variable of the specimen was obtained. As shown in Figure 17, the evolution curve can well reflect the damage variation trend of the rock-like specimen under various cycles. It can be found that the damage variable value of each specimen did not reach 1 after the failure. Due to the difference in the crack inclination of each specimen, the elastic modulus varies in the process of cyclic loading and unloading, which leads to the different amplitude of 


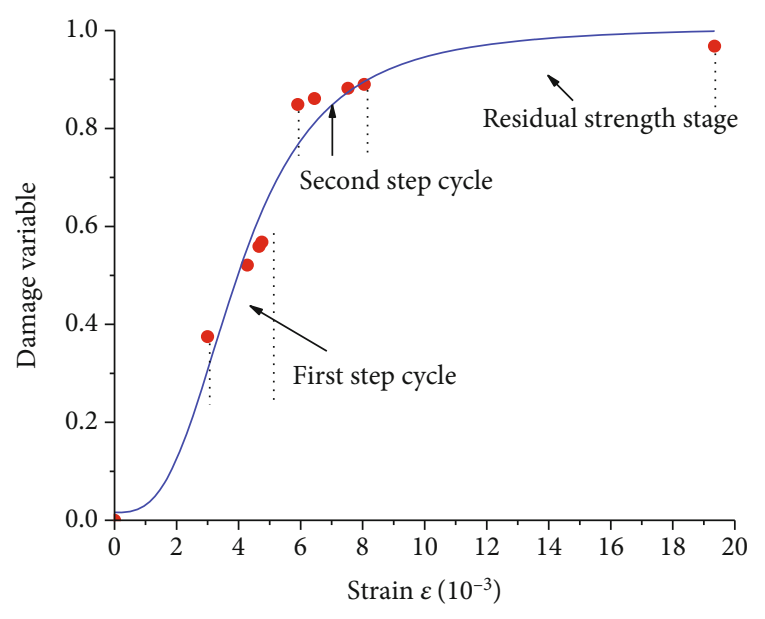

Figure 16: Damage evolution curve for specimen B00.

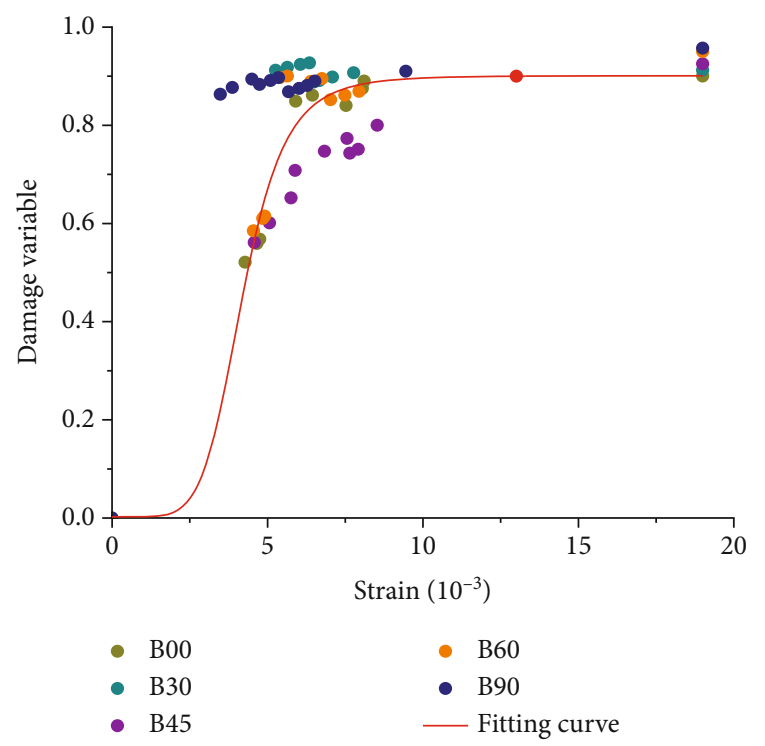

FIGURE 17: Damage evolution curve for specimens of group B.

the fluctuation of the damage variable of the specimen. For example, the elastic modulus of samples B30 and B90 increases sharply in the first-stage cyclic loading and unloading process, leading to a particularly large damage variable value, which is close to the value of failure.

\section{Conclusions}

(1) Under staged cyclic loading and unloading, the fatigue failure deformation of a noncoplanar intermittent fractured rock mass and an intact rock mass are basically the same as the deformation corresponding to the intersection point of the postpeak area under a static load, and with an increase in the stress amplitude, the fracture plastic deformation characteristics of the specimen become obvious. The trajectory distance of the loading-unloading curves increased, the shape of the hysteresis loop changed, and the area also increased
(2) The fatigue failure of a rock mass with noncoplanar discontinuous fractures is affected by the distribution of fractures and penetration mode. Both ends of the horizontal main fractures are the main stress concentration areas, and they inhibited the initiation of cracks in the inclined fractures. As the inclination angle increased, the inhibitory effect became more obvious. Parallel double cracks have a certain strengthening effect on the failure strength of the specimen, and the failure of the specimen indicates significant brittleness

(3) When the lower stress limit was constant, energy dissipation in the specimen increased with the increase in the upper limit stress, but the energy dissipation was relatively stable in each step cycle. As the inclination angle of the secondary crack increased, the increase in energy dissipation value decreased, the internal microstructure was adjusted because the prefabricated cracks were gradually compacted, and the cracks expanded and penetrated, resulting in greater fluctuations in the dynamic elastic modulus of the specimen. As the loading progressed, the dynamic elastic modulus exhibited a downward trend, and the change in the damping ratio was greatly affected by the dynamic elastic modulus and the area of the hysteresis loop. These factors overcome the energy dissipation of the damping force, and, along with changes in the degree of damage to the specimen, they determine the evolution form of the damping ratio curve

(4) Based on the Weibull probability distribution function, the evolution curve of the damage variable of the specimen was obtained. The evolution curve reflects the damaged trend of the rocklike specimen under various cycles. However, the influence of the number of cycles and the amount of initial damage and the brittle-plastic transition of the specimen under staged cycle loading and unloading were not fully considered. This is also a problem to be addressed in future studies

\section{Data Availability}

All data used in this study can be obtained by contacting the corresponding author (Wen-yuan $\mathrm{Wu}$ ), email address: wwyuan94@163.com.

\section{Conflicts of Interest}

The authors declare no conflicts of interest related to the publication of this paper.

\section{Authors' Contributions}

Wen-yuan $\mathrm{Wu}$ is responsible for the methodology and conceptualization. Gui-cheng $\mathrm{He}$ is responsible for the investigation and data curation. Yong-ming Xue is responsible for the writing of the original draft, validation, and visualization. 
Yun Wang is responsible for the resources and writing of the review and editing. Bing Dai is responsible for the supervision.

\section{Acknowledgments}

This study was supported by the National Natural Science Foundation of China (51974163, 51804164, and 51774187) and the Key Scientific Research Foundation of Hunan Provincial Education Department (18A248 and 17A184). Thanks to the Hunan Province \& Hengyang City Engineering Technology Research Center for Disaster Prediction and Control on Mining Geotechnical Engineering (2019TP2070) for providing experimental platform support.

\section{References}

[1] Z. Rusin and P. Swiercz, "Frost resistance of rock materials," Construction and Building Materials, vol. 148, pp. 704-714, 2017.

[2] M. P. Kuzmin, L. M. Larionov, V. V. Kondratiev, M. Y. Kuzmina, V. G. Grigoriev, and A. S. Kuzmina, "Use of the burnt rock of coal deposits slag heaps in the concrete products manufacturing," Construction and Building Materials, vol. 179, pp. 117-124, 2018.

[3] S. Wang, S. Licheng, L. Xibing et al., "Experimental investigation of cuttability improvement for hard rock fragmentation using conical cutter," International Journal of Geomechanics, vol. 21, no. 2, p. 06020039, 2021.

[4] Z. Song, T. Frühwirt, and H. Konietzky, "Inhomogeneous mechanical behaviour of concrete subjected to monotonic and cyclic loading," International Journal of Fatigue, vol. 132, p. 105383, 2020.

[5] Y. Luo, F. Q. Gong, X. B. Li, and S. Y. Wang, "Experimental simulation investigation of influence of depth on spalling characteristics in circular hard rock tunnel," Journal of Central South University, vol. 27, no. 3, pp. 891-910, 2020.

[6] Y. Wang, C. H. Li, and J. Q. Han, "On the effect of stress amplitude on fracture and energy evolution of pre-flawed granite under uniaxial increasing-amplitude fatigue loads," Engineering Fracture Mechanics, vol. 240, p. 107366, 2020.

[7] J. Q. Xiao, D. X. Ding, G. Xu, and F. Jiang, "Waveform effect on quasi-dynamic loading condition and the mechanical properties of brittle materials," International Journal of Rock Mechanics and Mining Sciences, vol. 45, no. 4, pp. 621-626, 2008.

[8] Z. Song, H. Konietzky, and M. Herbst, "Bonded-particle model-based simulation of artificial rock subjected to cyclic loading," Acta Geotechnica, vol. 14, no. 4, pp. 955-971, 2019.

[9] M. N. Bang and V. Petros, "Fatigue properties of intact sandstone samples subjected to dynamic uniaxial cyclical loading," International Journal of Rock Mechanics\&Mining Sciences, vol. 42, no. 2, pp. 237-250, 2005.

[10] Z. Song, Y. Wang, H. Konietzky, and X. Cai, "Mechanical behavior of marble exposed to freeze-thaw-fatigue loading," International Journal of Rock Mechanics and Mining Sciences, vol. 138, p. 104648, 2021.

[11] K. Peng, J. Q. Zhou, Q. Zou, J. Zhang, and F. Wu, "Effects of stress lower limit during cyclic loading and unloading on deformation characteristics of sandstones," Construction and Building Materials, vol. 217, pp. 202-215, 2019.
[12] B. Sun, Z. Zhu, and C. Shi, "Dynamic mechanical behavior and fatigue damage evolution of sandstone under cyclic loading," International Journal of Rock Mechanics \& Mining Sciences, vol. 94, pp. 82-89, 2017.

[13] X. M. Li, C. Y. Liu, S. P. Syd, and Y. Lu, "Fatigue deformation characteristics and damage model of sandstone subjected to uniaxial step cyclic loading," Journal of China university of mining and technology, vol. 46, no. 1, pp. 8-17, 2017.

[14] X. S. Liu, J. G. Ning, Y. L. Tan, and Q. H. Gu, "Damage constitutive model based on energy dissipation for intact rock subjected to cyclic loading," International Journal of Rock Mechanics and Mining Sciences, vol. 85, pp. 27-32, 2016.

[15] E. Liu, R. Huang, and S. He, "Effects of frequency on the dynamic properties of intact rock samples subjected to cyclic loading under confining pressure conditions," Rock Mechanics and Rock Engineering, vol. 45, no. 1, pp. 89-102, 2012.

[16] J. Liu, H. Xie, Z. Hou, C. Yang, and L. Chen, "Damage evolution of rock salt under cyclic loading in unixial tests," Acta Geotechnica, vol. 9, no. 1, pp. 153-160, 2014.

[17] T. T. Li, X. J. Pei, and D. P. Wang, "Nonlinear behavior and damage model for fractured rock under cyclic loading based on energy dissipation principle," Engineering Fracture Mechanics, vol. 206, pp. 330-341, 2019.

[18] M. X. Liu and E. L. LIU, "Dynamic mechanical properties of artificial jointed rock samples subjected to cyclic triaxial loading," International Journal of Rock Mechanics and Mining Sciences, vol. 98, no. 10, pp. 54-66, 2017.

[19] N. Li, W. Chen, P. Zhang, and G. Swoboda, “The mechanical properties and a fatigue-damage model for jointed rock masses subjected to dynamic cyclical loading," International Journal of Rock Mechanics and Mining Sciences, vol. 38, no. 7, pp. 1071-1079, 2001.

[20] S. Wang, X. Li, J. Yao et al., "Experimental investigation of rock breakage by a conical pick and its application to non-explosive mechanized mining in deep hard rock," International journal of rock mechanics and mining sciences, vol. 122, p. 104063, 2019.

[21] J. JIN, P. CAO, Y. CHEN, C. Pu, D. Mao, and X. Fan, "Influence of single flaw on the failure process and energy mechanics of rock- like material," Computers and Geotechnics, vol. 86, pp. 150-162, 2017.

[22] X. P. Zhang, Q. Zhang, and S. Wu, "Acoustic emission characteristics of the rock-like material containing a single flaw under different compressive loading rates," Computers and Geotechnics, vol. 83, pp. 83-97, 2017.

[23] J. J. Zeng, Z. J. Zhang, X. X. Zhang, and C. Z. Pu, "Fracture test and analysis of horizontal fissure rock-like specimens influenced by apertures," Chinese Journal of Geotechnical Engineering, vol. 42, no. 3, pp. 523-532, 2020.

[24] Y. Wang, W. K. Feng, R. L. Hu, and C. H. Li, "Fracture evolution and energy characteristics during marble failure under triaxial fatigue cyclic and confining pressure unloading (FCCPU) conditions," Rock Mechanics and Rock Engineering, vol. 54, no. 2, pp. 799-818, 2021.

[25] T. Liu, B. Lin, Q. Zou, C. Zhu, and F. Yan, "Mechanical behaviors and failure processes of precracked specimens under uniaxial compression: a perspective from microscopic displacement patterns," Tectonophysics, pp. 104-120, 2016.

[26] S. Miao, P. Pan, Z. Wu, S. Li, and S. Zhao, "Fracture analysis of sandstone with a single filled flaw under uniaxial compression," Engineering Fracture Mechanics, vol. 204, pp. 319-343, 2018. 
[27] Y. Wang, W. K. Feng, H. J. Wang, C. H. Li, and Z. Q. Hou, "Rock bridge fracturing characteristics in granite induced by freeze-thaw and uniaxial deformation revealed by AE monitoring and post-test CT scanning," Cold Regions Science and Technology, vol. 177, p. 103115, 2020.

[28] H. F. Deng, Y. Hu, J. L. Li, W. Zhe, Z. Xiao-jing, and Z. Hengbin, "Effects of frequency and amplitude of cyclic loading on the dynamic characteristics of sandstone," Rock and soil mechanics, vol. 38, no. 12, 2017.

[29] B. MCKAVANAGH and F. D. STACEY, "Mechanical hysteresis in rocks at low strain amplitudes and seismic frequencies," Physics of the Earth and Planetary Interiors, vol. 8, no. 3, pp. 246-250, 1974.

[30] B. J. Brennan and F. D. Stacey, "Frequency dependence of elasticity of rock-test of seismic velocity dispersion," Nature, vol. 268, no. 5617, pp. 220-222, 1977.

[31] M. L. Zhu, Z. D. Zhu, G. Li, Y. Qiu, Z. Chen, and J. Li, “Experimental study of dynamic characteristics of granite under cyclic loading," Chinese journal of rock mechanics and Engineering, vol. 28, no. 12, pp. 2520-2526, 2009.

[32] J. F. Liu, J. Xu, Q. S. Li, and G. L. Li, "Experimental study of rock damping parameters under cyclic loading," Chinese journal of rock mechanics and Engineering, vol. 29, no. 5, pp. 10361041, 2010.

[33] Z. L. Wang, Y. C. Li, and J. G. Wang, "A damage-softening statistical constitutive model considering rock residual strength," Computers \& Geosciences, vol. 33, no. 1, pp. 1-9, 2007.

[34] Y. Q. Zhao, H. Y. Liu, S. R. Lu, and L. Zhang, "Damage constitutive model of jointed rock mass based on coupling macroscopic and microscopic flaws," Journal of central south university (natural science edition), vol. 46, no. 4, pp. 14891496, 2015.

[35] N. Xie, Q. Z. Zhu, L. H. Xu, and J. F. Shao, "A micromechanicsbased elastoplastic damage model for quasi-brittle rocks," Compters and Geotechnics, vol. 38, no. 8, pp. 970-977, 2011.

[36] J. W. Zhou, W. Y. Xu, and X. G. Yang, "A microcrack damage model for brittle rocks under uniaxial compression," Mechanics Research Communications, vol. 37, no. 4, pp. 399-405, 2010.

[37] N. Halakatevakis and A. L. Sofianos, "Strength of a blocky rock mass based on an extended plane of weakness theory," International Journal of Rock Mechanics \& Mining Sciences, vol. 47, no. 4, pp. 568-582, 2010. 